\title{
O PENSAMENTO DE PAULO FREIRE NO CONTEXTO DA FORMAÇÃO DE EDUCADORES DO MST
}

\author{
THE THOUGHT OF PAULO FREIRE IN THE CONTEXT OF \\ THE TRAINING OF EDUCATORS OF THE MST \\ EL PENSAMIENTO DE PAULO FREIRE EN EL CONTEXTO \\ DE LA FORMACIÓN DE EDUCADORES DEL MST
}

\section{Marle Aparecida Fideles de Oliveira Vieira ${ }^{1}$ \\ Valdete Côco ${ }^{2}$}

RESUMO: Este artigo tematiza as contribuições de Paulo Freire na abordagem da formação dos educadores do campo, a partir de dados de pesquisa que objetivou compreender como se efetiva a formação continuada dos educadores que atuam em Assentamentos do Movimento dos Trabalhadores Rurais Sem Terra (MST). Em diálogo com os referenciais teórico-metodológicos bakhtinianos, as contribuições de Paulo Freire sustentam a análise de dados decorrentes de entrevista semiestruturada realizada com um gestor municipal da educação do campo, além da roda de conversa desenvolvida com o Setor de Educação do MST que integra o município pesquisado. Os dados apontam referências à possibilidade de uma formação articulada pelo movimento social organizado, alicerçada na vida dos educadores e engajada com os sujeitos do campo. O artigo demonstra a atualidade do pensamento de Freire nas ações político-pedagógicas realizadas em assentamentos de Reforma Agrária.

PAlavraS-Chave: Paulo Freire. Formação dos Educadores. Movimento dos trabalhadores rurais sem terra.

\begin{abstract}
This article discusses the contributions of Paulo Freire to the training of rural educators, based on research data that aims to understand how the continuing education of educators working in Settlements of the Movement of Landless Rural Workers (MST) is effective. In a dialogue with the Bakhtinian theoreticalmethodological references, Paulo Freire's contributions support the analysis of data resulting from a semistructured interview conducted with a municipal manager of the education of the field, in addition to the discussion thread developed with the MST Education Sector that integrates the municipality. The data point to references to the possibility of a formation articulated by the organized social movement, based on the life of the educators and engaged with the subjects of the field. The article demonstrates the current relevance of Freire's thinking in political-pedagogical actions carried out in Agrarian Reform settlements.
\end{abstract}

KEYWORDS: Paulo Freire. Training of educators. Movement of landless rural workers.

RESUMÉN: Este articulo tematiza las contribuciones de Paulo Freire en el abordaje de la formación de los educadores del campo, a partir de datos de investigación, que objetivó comprender como se efectiva la formación continua de los educadores que actúan en el Asentamiento del Movimiento de los trabajadores Rurales Sin Tierra (MST). En concertación a los referenciales teórico-metodológicos bakhtinianos, las contribuciones de Paulo Freire sostienen el análisis de datos resultantes de entrevista semiestructurada realizada con un gestor municipal de la educación del campo, además de la rueda de conversación desarrollada con el Sector de Educación del MST, del Estado que integra el municipio investigado. Los datos apuntan referencias a la posibilidad de una formación articulada por el movimiento social organizado, basado en la vida de los educadores y comprometida con los sujetos del campo. El artículo demuestra la actualidad del pensamiento de Freire en las acciones político-pedagógicas realizadas en asentamientos de Reforma Agraria.

PALABRAS Clave: Paulo Freire. Formación de educadores. Movimiento de los trabajadores rurales sin tierra.

\footnotetext{
${ }^{1}$ Submetido em: 29/11/2017 - Aceito em: 22/02/2018 - Publicado em: 03/06/2018.
}

\begin{tabular}{|c|c|c|c|c|c|c|}
\hline (C) Rev. Educ. Perspec. & Viçosa, $M G$ & v.9 & n.1 & p.159- 173 & jan./abr. 2018 & eISSN 2178-8359 \\
\hline
\end{tabular}




\section{INTRODUÇÃO}

Neste artigo, tematizamos as contribuições de Paulo Freire na abordagem da formação dos educadores do campo, a partir de dados obtidos em pesquisa que buscou compreender como se efetiva a formação continuada dos educadores que atuam em assentamentos do Movimento dos Trabalhadores Rurais Sem Terra (MST). Utilizando referencial bakhtiniano em articulação com pressupostos de Paulo Freire, a pesquisa qualitativa exploratória foi realizada em um município integrante de um Estado da Região Sudeste. Na pesquisa foram mobilizados os seguintes procedimentos e instrumentos: desenvolvimento de observação em dois encontros estaduais dos educadores e educadoras da Reforma Agrária, realizados no município pesquisado (nos anos de 2014 e 2015); aplicação de questionário ao coletivo de 98 educadores que trabalham em assentamentos; entrevistas semiestruturadas com o gestor da educação do campo (GEC) do município pesquisado e com uma educadora atuante na educação infantil (EEI); roda de conversa com o Setor de Educação (SE) do MST e observação no contexto de uma instituição de Educação Infantil do Campo (EIC).

Considerando os desafios impostos ao movimento social organizado e ao Poder Público na garantia da formação, foram utilizadas, para o escopo deste texto, as contribuições de Paulo Freire acerca da formação dos educadores do campo na discussão sobre os conceitos de práxis pedagógica e de diálogo. Nesse sentido, compreendemos que a formação se dá no processo educativo, no fazer-se educador engajado com as questões sociais da realidade da vida das pessoas e da comunidade. Nessa direção:

A obra de Paulo Freire contribuiu na formulação educacional do Movimento, por
ver a educação como essencialmente política, por sua contribuição para a educação
dos oprimidos, pela perspectiva dialética para a produção do conhecimento, pela
ênfase no direito à palavra, à participação e ao diálogo (DALMAGRO, 2011, p. 65).

Assim, as contribuições de Paulo Freire permitem dialogar com os pressupostos bakhtinianos, sobretudo marcando a importância de considerar os movimentos interativos que mobilizam as enunciações, instando a processualidade da (re)composição do diálogo com suas múltiplas pautas em disputa. No bojo da afirmação do diálogo como movimento coletivo - sem com isso invisibilizar os silenciamentos e as imposições de estratégias de calar -, neste texto, focalizamos a formação, destacando as contribuições do pensamento de Paulo Freire contextualizadas nas vivências que marcam os assentamentos do MST. Para desenvolver esse propósito, foram selecionados os enunciados do GEC e do SE, dirigidos aos encaminhamentos da formação dos educadores. Para situar as reflexões desenvolvidas, no primeiro movimento deste artigo, contextualizamos a construção recente da Educação do Campo (EC) no país, como forma de alicerçar os percursos em torno dessa política pública. No segundo movimento, destacamos as contribuições de Paulo Freire acerca da formação dos

\begin{tabular}{|c|c|c|c|c|c|c|} 
(C) Rev. Educ. Perspec. & Viçosa, $M G$ & v.9 & n.1 & p.159- 173 & jan./abr. 2018 & eISSN 2178-8359 \\
\hline
\end{tabular}


educadores, dada a atualidade do pensamento freiriano e as possibilidades de sua vinculação ao contexto da educação no MST.

\section{BREVE CONTEXTO DA EDUCAÇÃO DO CAMPO NO BRASIL}

É importante historicizar que a formação pensada para os povos que habitam o campo se alicerçava em uma educação “[...] vinculada à ideologia do capitalismo agrário [...] construída a partir das equipes governamentais, do poder executivo, para a sociedade civil, sem considerar e reconhecer as experiências dos coletivos organizados [...]" (SOUZA, 2015, p. 148), ou seja, a conhecida educação rural. Em contraposição a esse tipo de educação, arquiteta-se a EC, uma construção recente, que reivindica uma política de educação para a população do campo pautada na busca por considerar as pessoas, as comunidades e os saberes historicamente construídos, a fim de reconhecer os sujeitos como protagonistas do processo educativo (FONEC, 2012).

Importa também ressaltar que as discussões em torno da EC se consolidaram a partir do ano de 1997, com a realização do I Encontro Nacional de Educadoras e Educadores da Reforma Agrária (Enera). Esse encontro se tornou marco referencial para a temática, numa perspectiva de considerar as pessoas e suas histórias de vida, de luta e de resistência. A partir dessa pauta, nascia

[...] uma educação que afirmava a importância de um novo projeto para a agricultura, na defesa da Reforma Agrária; uma educação vinculada aos processos de mudanças necessárias na sociedade; uma educação em que os protagonistas são os movimentos sociais e os sujeitos do campo. Para tanto, nascia um projeto de educação que se contrapunha à educação rural, até então pensada para os sujeitos do campo, e não com os sujeitos do campo (VIEIRA; CÔCO, 2016, p. 94, grifo original).

Ao tratarmos de uma construção coletiva, que alicerça as discussões e articulações em torno de um projeto de educação, cabe lembrarmos Freire (2004, p. 101) na afirmação de que:

\footnotetext{
Seria demasiado ingênuo, até angelical de nossa parte, esperar que a 'bancada ruralista' aceitasse, quieta e concordante, a discussão, nas escolas rurais e mesmo urbanas do país, da reforma agrária como projeto econômico político e ético da maior importância para o próprio desenvolvimento nacional. Isso é tarefa para educadores e educadoras [...] cumprir dentro e fora das escolas.
}

Assim, as assertivas de Freire podem ser tomadas como uma convocação aos educadores do campo a trabalhar em proximidade com os sujeitos que vivem construindo diariamente suas histórias de vida e resistência no campo, mais do que isso, perspectivam a construção de um pertencimento comum. Nesse contexto, destacamos a tarefa afirmada pelos educadores do MST, ao enfatizarem a importância de promover uma educação vinculada à materialidade da

\begin{tabular}{l|c|c|c|c|c|c} 
(C) Rev. Educ. Perspec. & Viçosa, $M G$ & v.9 & n.1 & p.159- 173 & jan./abr. 2018 & eISSN 2178-8359 \\
\hline
\end{tabular}


vida das pessoas, compondo conjuntamente esse projeto de educação. Nesse propósito, aos educadores do campo e aos movimentos sociais incumbe "[...] perceber as contradições no decorrer dos processos e trabalhá-las [...] para buscar garantir as mudanças que queremos: Uma escola que esteja a serviço da emancipação humana" (VARGAS, 2010, p. 224).

No desafio de engendrar essa escola construída com os sujeitos do campo, tomamos como contexto de abordagem o campo da educação infantil, para reiterar que o projeto educacional campesino precisa abarcar as diferentes etapas, modalidades e níveis de ensino, com vistas a afirmar a garantia plena do direito à educação (VIEIRA; CÔCO, 2016). Nos limites de um artigo, para dar conta da focalização proposta, não se podem explorar possíveis características e demandas próprias a cada etapa, nível ou modalidade de ensino. Ainda assim, importa acentuar a necessária articulação entre a abrangência do projeto educativo e o respeito às especificidades de cada faixa etária de atendimento. Com isso, realçando o compromisso com as interlocuções estabelecidas no desenvolvimento da pesquisa (VIEIRA, 2016), enfatizamos a necessidade de atenção à especificidade da educação das crianças pequenas, no bojo da configuração do projeto educativo do campo.

Voltando à abordagem do conjunto desse projeto, é preciso ainda considerar com especial atenção a formação dos educadores vinculada aos propósitos do projeto da EC. Nessa pauta é relevante entender que:

\footnotetext{
No plano da práxis pedagógica, a Educação do Campo projeta futuro quando recupera o vínculo essencial entre formação humana e produção material da existência, quando concebe a intencionalidade educativa na direção de novos padrões de relações sociais, pelos vínculos com novas formas de produção, com o trabalho associado livre, com outros valores e compromissos políticos, com lutas sociais que enfrentam as contradições envolvidas nesses processos (CALDART, 2012, p. 265).
}

Nutrindo as lutas para a efetivação da EC, destacamos as assertivas de Freire sobre a práxis para lembrar que ela "[...] é reflexão e ação dos homens sobre o mundo para transformá-lo" (FREIRE, 1987, p. 38). Considerando os desafios que persistem na transformação do mundo com vistas à realização da $\mathrm{EC}$, reiteramos a aposta na ação mobilizadora de novos horizontes para os processos educativos. Perquirindo essa aposta, focalizamos, a seguir, as contribuições de Paulo Freire na abordagem da formação de educadores. Para isso, foram selecionados da pesquisa realizada os enunciados produzidos em entrevista com um GEC e em roda de conversa com o SE, na perspectiva de afirmar a possibilidade de uma educação emancipadora, em que todos os sujeitos envolvidos no processo educativo sejam protagonistas, tanto nos processos de planejamento e deliberações quanto na execução e avaliação das ações. 


\title{
PAULO FREIRE E A FORMAÇÃO DE EDUCADORES
}

Ao destacar a formação dos educadores do campo, em específico a dos que atuam em assentamentos de Reforma Agrária e, mais particularmente, de assentamentos vinculados ao MST, faz-se necessário considerar que os espaços e tempos de atuação nas escolas do campo alargam a noção de trabalho em sala de aula. Esse alargamento requer do educador vinculação com a comunidade, conhecimento de seus desafios e participação nas suas lutas, de modo a construir um engajamento nas causas mais amplas que abarcam a educação. Com esse entendimento, podemos afirmar que:

\begin{abstract}
A proposta educacional de Paulo Freire parte do princípio de que toda e qualquer atividade pedagógica constitui uma ação cultural. Porém, a contradição social entre opressores e oprimidos dá à educação duas possibilidades distintas: (1) educação como ação cultural para a domesticação que, baseando-se numa prática antidialógica, leva os educadores ao silêncio e à conseqüente perpetuação da ordem social vigente; (2) educação como ação cultural para a liberdade que, fundamentando-se numa prática dialógica, conduz a mudanças sociais significativas. Enquanto a primeira é rígida e autoritária, a segunda é crítica e participativa (OLIVEIRA, 1996a, p. 19).
\end{abstract}

Tomando essa distinção nos propósitos da ação pedagógica em cotejo com os pressupostos de engajamento com o contexto da $\mathrm{EC}$, “[...] não é possível à escola, se, na verdade, engajada na formação de educandos educadores, alhear-se das condições sociais, culturais, econômicas de seus alunos, de suas famílias, de seus vizinhos" (FREIRE, 2004, p. 68), como também não é possível aos educadores alhear-se ao contexto da escola e da comunidade. Assim, movendo uma dialogia com os pressupostos bakhtinianos, o processo educativo pode ser afirmado como ato responsável, movido com as assinaturas dos educadores no encontro com as múltiplas pautas que interagem com a educação.

No movimento de reconhecer a importância da educação freiriana e dirigi-la à EC, especialmente à formação dos educadores, os dados da pesquisa informam que há mobilizações do MST para tornar presentes as contribuições de Freire, sobretudo nas práticas realizadas nas escolas do campo. Quando os educadores destacam os objetivos do MST para a luta pela educação, afirmam que: “[...] o MST não tem uma luta só pela terra, como está lá nos objetivos, nós lutamos pela transformação da sociedade, pra isso é essencial o centro de formação, incluindo aí a educação" (SE).

Assim, o SE, ao reconhecer a relevância da educação no processo de uma luta mais ampla - a transformação da sociedade - vai ao encontro dos enunciados do GEC acerca da importância da formação:

O primeiro elemento é o processo de desconstrução [...]. Eu acho que a formação é um elemento tático pra desconstrução. Desconstrução de pensamentos hegemônicos

\begin{tabular}{l|c|c|c|c|c|c} 
(C) Rev. Educ. Perspec. & Viçosa, $M G$ & v.9 & n.1 & p.159- 173 & jan./abr. 2018 & eISSN 2178-8359 \\
\hline
\end{tabular}


da sociedade capitalista ocidental. Então, você tem que desconstruir isso, não tem jeito [...] quando você faz uma formação e ela está paralela à sua prática, essa formação ela não desconstrói. Ela passa a ser meramente informações. Quando você relaciona a formação do educador com a sua prática, ele vai refletir a sua prática. E é nesse processo de reflexão de sua prática que acontece o processo de desconstrução (GEC).

$\mathrm{Na}$ centralidade dos processos formativos - mobilizando possibilidades de construção e desconstrução de referenciais e compromissos para a atuação -, focalizamos também a importância da formação inicial e continuada para atuação nos espaços e tempos do campo, conforme assertivas da legislação brasileira (BRASIL, 1996; 2008; 2015). Reafirmamos, ainda, o direito dos educadores do campo à formação, articulada à especificidade da atuação nos espaços campesinos, conforme destacam Molina e Sá (2012, p. 468):

Este perfil de educador do campo que os movimentos demandam exige uma compreensão ampliada de seu papel, uma compreensão da educação como prática social, da necessária inter-relação do conhecimento, da escolarização, do desenvolvimento, da construção de novas possibilidades de vida e permanência nesses territórios pelas lutas coletivas dos sujeitos do campo; pretende-se formar educadores capazes de promover profunda articulação entre escola e comunidade.

Evidenciamos, portanto, a importância da formação vinculada à materialidade da vida e do fazer-se educador e educadora a partir da compreensão de que "[...] na formação permanente dos professores, o momento fundamental é o da reflexão crítica sobre a prática. É pensando criticamente a prática de hoje ou de ontem que se pode melhorar a próxima prática" (FREIRE, 2004, p. 45).

No encaminhamento das práticas, com destaque para as ações desenvolvidas pelo SE, constatamos uma luta coletiva pela educação:

[...] o setor de educação tem esse princípio, o princípio da coletividade, não é uma pessoa que vai pensar a educação, mas tem um coletivo que tem o papel de estar debatendo, já que a educação é uma ação complexa, que envolve diferentes dimensões. Então essa educação não pode ser resultado do pensamento de uma pessoa, ela tem que representar o pensamento de uma coletividade que tem um objetivo em comum (SE).

Essa afirmação demonstra o movimento dos educadores na pauta da EC, no sentido da aposta na força do coletivo, que se nutre na construção dialógica da vida (BAKHTIN, 2011). Ao tomarmos as assertivas de Freire em interação com os referenciais bakhtinianos, destacamos o contexto de negociação social que, no encontro (não sem confrontos), move as pautas em disputa. Conforme o escopo deste texto, o recorte da pauta educacional, com destaque para a formação dos educadores vinculados à EC, integra um contexto de disputa de projetos composto por distintas vozes que, no diálogo (considerando também silenciamentos e impossibilidades de dizer/formas de calar), vêm formulando a discussão sobre as (im)possibilidades da educação, da escola e dos processos formativos.

\begin{tabular}{l|c|c|c|c|c|c} 
(C) Rev. Educ. Perspec. & Viçosa, $M G$ & v.9 & n.1 & p.159- 173 & jan./abr. 2018 & eISSN 2178-8359 \\
\hline
\end{tabular}


No convite aos educadores para mover os processos formativos, é sempre importante lembrar que "[...] é como profissionais [...] na competência que se organiza politicamente que está talvez a maior força dos educadores - que eles e elas devem ver-se a si mesmos e a si mesmas" (FREIRE, 2004, p. 72). Diante dessa aposta organizativa, dirigida à construção coletiva de um projeto de vida comum, destacam-se, nos estudos de Freire, as referências ao diálogo. Como assinala Oliveira (1996b, p. 9-10),

Freire [...] não vê no ato dialógico uma tentativa de substituir conflitos inevitáveis por confrontações puramente verbais que devem ser consideradas como fins em si mesmas. Pelo contrário, o diálogo é visto por ele como sendo um método de investigação pedagógica, que faz com que as técnicas de ensino e aprendizagem sejam incorporadas não apenas a cada fragmento da verdade que possam aparecer em vários e diferentes posicionamentos teóricos, mas, também e acima de tudo, para assegurar o desenvolvimento dialético de sua própria verdade, considerando os elementos novos que emergem do contexto social. Por conseguinte, o diálogo estende-se até o limite em que uma prática dialogal constante seja estabelecida entre homens e a realidade, em processo de construção.

Com essa perspectiva dialógica (acenando pontos de aproximação aos referenciais bakhtinianos), é possível conceber um processo formativo vinculado à realidade, de modo que estar na escola, no assentamento, com a comunidade possibilita ao educador mobilizar engajamentos e comprometer-se com as lutas travadas por toda a comunidade assentada. No reconhecimento do homem como “[...] um ser da 'práxis'; da ação e da reflexão" (FREIRE, 2013, p. 30), cabe realçar também os ensinamentos de Freire sobre o vínculo entre essa reflexão e as possibilidades de agir. Desse modo, deve-se compreender que

A práxis é entendida como a possibilidade de refletir sobre a sua ação, o seu modo de agir diante do mundo. Logo, nesse agir, dá-se o entendimento de pertencimento a essa prática pedagógica diante do mundo. Quanto ao processo educativo e a sua relação com a formação para o trabalho com os educandos, a práxis se dá no sentido de (re)pensar essa ação e por meio dela buscar outras possibilidades de atuar e ajudar os educandos a questionar, problematizar questões que emergem no dia a dia nos espaços escolares e não escolares, permitindo que esses espaços sejam críticosreflexivos. Esse ato pedagógico por parte dos educadores é compreendido como práxis. Essa postura crítica diante do mundo, da vida, é o que Paulo Freire nos ensina (VIEIRA, 2016, p. 80).

Com esse entendimento, na escola do campo, não há espaço demarcado entre a sala de aula e o chão do assentamento. Tudo é educação, tudo é aprendizado, é tudo ao mesmo tempo. Nesse espaço/tempo, compreendemos com Bakhtin (2011, p. 128) que "o homem vivente se estabelece ativamente de dentro de si mesmo no mundo [...]: eu ajo através do ato, da palavra, do pensamento [...] eu vivo, eu me torno um ato [...]". Assim, a escola do campo se afirma como um espaço de conhecimento vivo, onde se aprende em todo o contexto, num lugar em que não se separa vida escolar e vida comunitária. Para Correia e Bonfim (2008, p. 63), “como Freire, nós educadores não podemos, jamais, aceitar que a prática educativa deva ater-

\begin{tabular}{l|c|c|c|c|c|c} 
(C) Rev. Educ. Perspec. & Viçosa, $M G$ & v.9 & n.1 & p.159- 173 & jan./abr. 2018 & eISSN 2178-8359 \\
\hline
\end{tabular}


se tão somente à 'leitura da palavra', à 'leitura do texto', mas que necessariamente deve aterse também à 'leitura do contexto', à 'leitura do mundo'”.

No pertencimento a uma educação alicerçada na vida dos sujeitos campesinos, compreendemos, pois, que a formação dos educadores do campo deve levar em consideração as bases legais que assinalam:

[...] $\S 2^{\circ}$ A admissão e a formação inicial e continuada dos professores e do pessoal de magistério de apoio ao trabalho docente deverão considerar sempre a formação pedagógica apropriada à Educação do Campo e às oportunidades de atualização e aperfeiçoamento com os profissionais comprometidos com suas especificidades (BRASIL, 2008, p. 2).

Na luta pelo direito à formação, no comprometimento com a EC e na observação dos desafios presentes na realidade em que vivem e atuam, os educadores participantes da pesquisa destacam a educação como um projeto em disputa:

Num primeiro momento a luta maior é pela escola no assentamento e aí há um envolvimento muito grande das famílias. Hoje a luta por escola ainda continua, mas existe outro enfrentamento aí que é a disputa pelo projeto de educação. Então talvez a luta por escola ficou menos destacada, mas a luta pelo projeto de educação está muito mais acirrada [...]. Então um grande desafio pra nós é a questão da formação (SE).

$\mathrm{Na}$ focalização desse tema, é importante indagarmos que tipo de sociedade temos e quais são seus princípios em vinculação com as concepções de educação que estão em disputa na compreensão da função social da escola e do papel de professor em face aos projetos que se apresentam (FERREIRA et al., 2005). Essas questões foram destacadas no II Encontro Nacional de Educadores e Educadoras da Reforma Agrária (Enera), informando o contexto em que a educação brasileira tem sido gestada:

\begin{abstract}
Além do histórico objetivo de garantir a formação dos trabalhadores e trabalhadoras a serviço do lucro das empresas, agora fazem da educação um ramo de seus negócios e buscam assumir o controle político e pedagógico das escolas [...]. Primeiro, buscam demonstrar que a escola pública está em crise, que educandos e educandas não aprendem, professores e professoras não sabem ensinar e o sistema educacional não funciona. Depois, apresentam como alternativa que as escolas passem a funcionar de acordo com a lógica de trabalho e de gestão das empresas capitalistas. Isso significa o estabelecimento de metas a serem atingidas, controle externo do processo pedagógico, perda de autonomia do trabalho dos educadores e das educadoras, responsabilização individual pela aprendizagem dos educandos e educandas sob qualquer condição e currículos determinados em função da avaliação em larga escala. Defendem, que para maior eficiência do modelo, as próprias empresas assumam a gestão das escolas, recebendo recursos públicos para esta tarefa. No Brasil esses grandes grupos empresariais se organizam no 'Movimento Todos pela Educação’ (II ENERA, 2015, s.p.).
\end{abstract}

Em vista dessa análise, evidenciamos a atualidade do pensamento de Freire, ao pautar uma educação comprometida com os sujeitos e não a serviço do capital. Nos investimentos para

\begin{tabular}{l|c|c|c|c|c|c} 
(C) Rev. Educ. Perspec. & Viçosa, $M G$ & v.9 & n.1 & p.159- 173 & jan./abr. 2018 & eISSN 2178-8359 \\
\hline
\end{tabular}


avançar nesse comprometimento, os educadores destacam a importância dos encontros realizados pelo SE:

[...] quando a gente tem os encontros estaduais, regionais, acho que um dos objetivos é assim, tentar dar unidade e ver o que nós estamos fazendo, [...] que formação nós estamos fazendo, [...] revisitando nossas práticas, o que nós realmente estamos fazendo lá (SE).

Ao revisitarem as práticas, os educadores fazem uma análise acerca do que estão realizando em cada assentamento, além de promover troca de experiências e avaliar o trabalho coletivo, instando a mobilização de um diálogo permanente. Nesse diálogo, compreendemos "que cada palavra se apresenta como uma arena em miniatura onde se entrecruzam e lutam os valores sociais de orientação contraditória. A palavra revela-se, no momento de sua expressão, como produto da interação viva das forças sociais" (BAKHTIN, 2014, p. 67). Assim, esse processo se afirma na aposta ao diálogo coletivo, para evidenciar mais uma assertiva freiriana de que o diálogo se nutre "do amor, da humildade, da esperança, da fé, da confiança. Por isso [...] o diálogo comunica. E quando os dois pólos do diálogo se ligam assim, com amor, com esperança, com fé um no outro, se fazem críticos na busca de algo" (FREIRE, 2003, p. 115).

Nessa busca, reveladora de grandes tensionamentos, quando analisamos a maneira como se dá a atuação dos educadores que trabalham em assentamentos de Reforma Agrária,

É possível perceber aproximações da concepção de escola formulada pelo MST [...] com a Pedagogia do oprimido de Paulo Freire, concepção esta ancorada, portanto, em experiências educacionais profundamente ligadas a processos de luta e transformação social [...] (DALMAGRO, 2011, p. 47).

Na pesquisa com os educadores, sentimos a sua responsabilização, conforme destacado por Freire (1979, p. 19): “o compromisso, próprio da existência humana, só existe no engajamento com a realidade, de cujas 'águas' os homens verdadeiramente comprometidos ficam 'molhados', ensopados. Somente assim o compromisso é verdadeiro”.

Nos compromissos assumidos com a EC, especificamente em áreas de assentamento de Reforma Agrária, também foram elencadas as assertivas de Freire sobre o educador e sua formação:

[...] o educador é o sujeito da sua prática, cumprindo a ele criá-la e recriá-la por meio da reflexão sobre o seu cotidiano; a formação do educador deve ser permanente e sistematizada, porque a prática se faz e refaz; a prática pedagógica requer a compreensão da própria gênese do conhecimento, ou seja, de como ocorre o processo de conhecer; o programa de formação dos educadores é condição para o processo de reorientação curricular da escola (FREIRE, 1991, p. 80).

Assim, a formação do educador se desenvolve na relação com a vida da comunidade, das pessoas, no (re)fazer-se constante e em movimento, entendendo que "a educação para a

\begin{tabular}{|c|c|c|c|c|c|c|} 
(C) Rev. Educ. Perspec. & Viçosa, $M G$ & v.9 & n.1 & p.159- 173 & jan./abr. 2018 & eISSN 2178-8359 \\
\hline
\end{tabular}


libertação é um ato de conhecimento e um método de ação transformadora que os seres humanos devem exercer sobre a realidade" (FREIRE, 1976, p. 90).

Nas diversas ações assumidas pelos educadores do campo, na realização da pesquisa pudemos perceber que a formação continuada em muitos casos fica a cargo do movimento social organizado, instando a problematização acerca da responsabilidade do Poder Público com a educação. Dessa forma,

Reconhecemos que o Setor de Educação procura organizar as formações de acordo com a realidade e as especificidades da EC, seja por meio dos encontros ou das demais ações que organizam para debaterem a EC, a EIC e as experiências de educação que se concretizam em áreas de assentamento. Reconhecemos esta formação, mas também problematizamos e chamamos a atenção para a responsabilidade dos poderes públicos com os investimentos nos processos de formação continuada, conforme preveem os marcos legais da educação brasileira, uma vez que tem sido os próprios educadores os protagonistas e os responsáveis pelos percursos formativos (VIEIRA, 2016, p. 163).

Nessa direção, é preciso pensar em projetos de formação que propiciem

[...] aos sujeitos a possibilidade de, em um espaço definido, produzir o tempo da formação - da autoformação - em que o saber da prática é tematizado pelo coletivo, que em regra geral não vivencia cotidianamente experiências de troca, podendo produzir, a partir daí, redes de conhecimentos que ampliam e reorientam as concepções e as práticas cotidianas (PAIVA, 2010, p. 145, grifo do original).

Tematizando a formação ao longo da pesquisa e no encontro com os sujeitos que vivem e atuam nos espaços e tempos do campo, fortalecemos a compreensão de que a formação se desenvolve na vida, na prática cotidiana da sala de aula, nas lutas internas do assentamento, na conquista da terra, na luta por escola, por saúde e por um projeto de educação que contemple as especificidades do campo. Nesse sentido, Freire chama a atenção para a atitude comprometida:

\footnotetext{
Nossa atitude comprometida - e não neutra - diante da realidade que buscamos conhecer resulta, num primeiro momento, de que o conhecimento é processo que implica na ação-reflexão do homem sobre o mundo. Acontece, porém, que o caráter teleológico da unidade ação-reflexão, isto é, da práxis, com que o homem, transformando o mundo, se transforma, não pode prescindir daquela atitude comprometida que, desta forma, em nada prejudica nosso espírito crítico ou nossa cientificidade. O que não nos é legítimo fazer é pôr-nos indiferentes ao destino que possa ser dado a nossos achados por aqueles que, detendo o poder das decisões e submetendo a ciência a seus interesses, prescrevem suas finalidades às maiorias (FREIRE, 1976, p. 97).
}

Desse modo, "ao assumir a situação concreta em que estamos como condição desafiante, somos capazes de mudar-lhe a significação por meio de nossa ação" (FREIRE, 1976, p. 134). Nas ações necessárias à luta por uma educação emancipadora e por um processo de formação 
de educadores que contemple as especificidades do campo, também se faz necessário lutar por uma

[...] escola pública viva, democrática, sensível, aberta, permeável às trocas, [...] possibilitando acesso aos diversos saberes, [...] possibilitando o não-apagamento das diferenças, a não-cristalização dos papéis, a não-restrição aos conhecimentos formais; [...] possibilitando mudar a história (LEITE, 1996, p. 91).

Nessa direção, o GEC corrobora a importância de lutar pela educação pública, ao enfatizar que: "a nossa luta é pela educação pública [...] foi estabelecido historicamente pelos movimentos sociais que a nossa luta é pela educação pública”. Essa luta implica a ocupação dos espaços que movem as articulações em torno das políticas públicas. O GEC acrescenta ainda que

[...] nós temos o Comitê Municipal de Educação do Campo, e eu acho que esse instrumento ele tem que ser apropriado, apropriado mesmo, pelos dois grandes movimentos que nós temos aqui no município, que é o MST e o MPA [Movimento dos Pequenos Agricultores] (GEC).

Nas discussões com os sujeitos campesinos participantes da pesquisa, em especial os educadores, evidenciamos a atualidade e os desafios do engajamento com movimentos sociais do campo, num tempo em que a educação tem sido ferramenta de disputa, em que os saberes coletivos, construídos historicamente, têm sido reapropriados na direção de um "notório saber" pautado na economia, com vistas a servir aos anseios de uma sociedade patriarcal, desigual e capitalista. Com isso, urge mobilizar discussões que visibilizem as pessoas e suas histórias de vida e de resistência, nutrindo a luta por uma educação construída diariamente com outras pessoas. No escopo deste artigo, as contribuições e a atualidade do pensamento de Paulo Freire - nas questões que dizem respeito às demandas das pessoas que habitam o campo e, neste contexto, aos processos educativos e formativos construídos nas relações entre seres humanos -, evidenciam uma busca por uma educação libertadora, emancipadora, a serviço da humanização. Nessa busca, "as obras de Freire nos instigam a um debate sobre nossa prática pedagógica, nos convocando a uma educação dialogal e ativa, voltada para a responsabilidade social e política" (CORREIA; BONFIM, 2008, p. 64).

Ao falar aos sem-terra, ao longo de sua trajetória como educador popular, Freire marcou que:

O saber do sentido comum, esse que a gente diz, eu penso que isso é assim, esse saber que não tem rigorosidade, esse saber que toma meu corpo e meus sentidos sobre os quais eu não exerço uma certa vigilância, esse saber é importante, mas não o suficiente. Então o povo tem o direito de ter o outro saber [...]. O povo tem o direito de saber a teoria da prática do povo. Quer dizer: a prática do povo é absolutamente fundamental, mas a prática não é a teoria dela mesma. É preciso que o povo domine porque tem esse direito, domine a prática, ou a teoria da prática, ou o saber teórico (MST, 2001, p. 23-24). 
Considerando esse saber do povo, um saber construído historicamente, que tem o direito de se banhar de teoria, tematizamos, neste artigo, a formação de educadores no diálogo com Paulo Freire. Discussões sobre as formas como são alicerçadas as práticas educacionais levam à mobilização de outros saberes em direção a uma educação construída com os sujeitos que, habitando o campo, lutam para alterar as correlações de forças que vêm marcando os encaminhamentos da educação brasileira (a serviço do capitalismo). Nesse investimento, reiteramos a aposta de Paulo Freire de que cada um de nós possui conhecimento de alguma coisa, podendo dar sua parcela de contribuição para uma educação democrática, transformadora, em direção a um mundo melhor. Nesse sentido, compõe-se um processo de formação humana, pessoal e coletiva nos diversos tempos e espaços em que atuamos, entendendo a educação como possibilidade importante para a construção, sempre social, de novas perspectivas para a vida.

\section{CONCLUSÕES}

Nas discussões encaminhadas com este artigo, buscamos tematizar a atualidade do pensamento de Paulo Freire, em especial na abordagem dos processos formativos dos educadores. Focalizamos o contexto de assentamentos de Reforma Agrária, em vinculação com o MST, com vistas a indicar que trabalhar na EC implica construir, não sem desafios, percursos formativos que se dão na prática cotidiana das vivências com as crianças e suas famílias, com o conjunto da comunidade, com a luta pela terra e com vinculações ao movimento social. No encontro com esses percursos formativos e destacando as contribuições de Paulo Freire, reconhecemos a importância dos diversos espaços e tempos do campo como fundamentais no processo formativo tanto dos educadores como de toda a comunidade assentada, emergindo uma formação que se faz em conjunto. Interagindo também com referenciais bakhtinianos, as assertivas de Freire nos levam a afirmar que na convivência coletiva (e formadora), pautando questões que vivificam a própria luta, evidenciam-se contradições, dificuldades e conquistas, movendo os desafios na beleza de ser educador comprometido com as causas mais amplas da educação, implicadas com a transformação da sociedade.

Nesse chamamento aos educadores, não se pode esquecer a responsabilidade do Poder Público pelo direito à formação que, conforme demonstram os dados da pesquisa, muitas vezes é deixada a cargo exclusivamente do movimento social. Considerando os desafios presentes na EC, urge somar forças e envidar esforços para avançar no atendimento ao direito à educação dos povos campesinos, incluindo o investimento na formação dos educadores. 
Nesse quadro, Paulo Freire tem sido alicerce nas caminhadas realizadas pelo MST na trajetória da luta pela EC. Assim, reiteramos a atualidade do seu pensamento, das suas contribuições para a compreensão de uma educação popular, tecida pelo povo e não para ele.

\section{REFERÊNCIAS}

BAKHTIN, Mikhail Mikhailovitch. Estética da criação verbal. 6. ed. São Paulo: Editora WMF/Martins Fontes, 2011.

BAKHTIN, Mikhail Mikhailovitch. Marxismo e filosofia da linguagem. São Paulo: Hucitec, 2014.

BRASIL. Lei ${ }^{\circ}$ 9394, de 20 de dezembro de 1996. Estabelece as diretrizes e bases da educação nacional. Diário Oficial da União. Brasília, DF: Senado Federal, 1996.

BRASIL. Ministério da Educação. Conselho Nacional de Educação. Resolução no 2, de 28 abril de 2008. Estabelece diretrizes complementares, normas e princípios para o desenvolvimento de políticas públicas de atendimento da educação básica do campo. Disponível em: <http://portal.mec.gov.br/cne/arquivos/pdf/2008/rceb002_08.pdf>. Acesso em: 29 set. 2016.

BRASIL. Ministério da Educação. Conselho Nacional de Educação. Resoluçãa no $\mathbf{n}^{\mathbf{2}}$, de $\mathbf{1}^{\mathbf{0}}$ de julho de 2015. Define as diretrizes curriculares nacionais para a formação inicial em nível superior (cursos de licenciatura, cursos de formação pedagógica para graduados e cursos de segunda licenciatura) e para a formação continuada. Disponível em:

<http://pronacampo.mec.gov.br/images/pdf/res_cne_cp_02_03072015.pdf>. Acesso em: 28 set. 2016.

CALDART, Roseli Salete. Educação do campo. In: CALDART, Roseli Salete et al. (Org.). Dicionário da educação do campo. Rio de Janeiro: Expressão Popular, p. 257-265, 2012.

CORREIA, Wilson; BONFIM, Cláudia. Práxis pedagógica na filosofia de Paulo Freire: um estudo dos estágios da consciência. Trilhas Filosóficas, Caicó: RN, ano 1, n. 1, p. 55-66, jan./jun. 2008. Disponível em:

<http://periodicos.uern.br/index.php/trilhasfilosoficas/article/view/15>. Acesso em: 22 nov. 2014.

DALMAGRO, Sandra Luciana. A escola no contex to das lutas do MST. In: VENDRAMINI, Célia Regina; MACHADO, Ilma Ferreira (Org.). Escola e movimento social: experiências em curso no campo brasileiro. São Paulo: Expressão Popular, p. 43-77, 2011.

ENERA. II Encontro Nacional de Educadoras e Educadores da Reforma Agrária. Manifesto das educadoras e dos educadores da Reforma Agrária. Luziânia, Goiás, 2015. Disponível

\begin{tabular}{l|c|c|c|c|c|c} 
(C) Rev. Educ. Perspec. & Viçosa, $M G$ & v.9 & n.1 & p.159- 173 & jan./abr. 2018 & eISSN 2178-8359 \\
\hline
\end{tabular}


em: <http://www.mst.org.br/2015/10/01/educadores-da-reforma-agraria-lancam-manifestopela-educacao-durante-o-2-enera.html>. Acesso em: 3 nov. 2017.

FERREIRA, Ayala Lindabeth Dias et al. Formação de professores: dos limites à consolidação de uma formação crítica. In: BAHIA, Celi da Costa Silva; FELIPE, Eliana da Silva; PIMENTEL, Maria Olinda Silva de Souza (Org.). Práticas pedagógicas em movimento: infância, universidade e MST. Belém: Edufpa, p.169-184, 2005.

FONEC. Fórum Nacional de Educação do Campo. Notas para análise do momento atual da Educação do Campo. Brasília, 2012. Disponível em:

<http://www.educampoparaense.com.br/upload/arq_arquivo/2016/03/1354.pdf>. Acesso em: 31 jan. 2017.

FREIRE, Paulo. Ação cultural para a liberdade e outros escritos. Rio de Janeiro: Paz e Terra, 1976.

FREIRE, Paulo. Educação e mudança. Tradução de Moacir Gadotti e Lillian Lopes Martin. Rio de Janeiro: Paz e Terra, 1979.

FREIRE, Paulo. Pedagogia do oprimido. 17. ed. Rio de Janeiro: Paz e Terra, 1987.

FREIRE, Paulo. A educação na cidade. São Paulo: Cortez, 1991.

FREIRE, Paulo. Educação como prática da liberdade. 27. ed. Rio de Janeiro: Paz e Terra, 2003.

FREIRE, Paulo. Pedagogia da autonomia. Rio de Janeiro: Paz e Terra, 2004.

FREIRE, Paulo. Extensão ou comunicação? 16. ed. Rio de Janeiro: Paz e Terra, 2013.

LEITE, Maria Isabel Ferraz Pereira. O que falam de escola e saber as crianças da área rural? Um desafio da pesquisa no campo. In: KRAMER, Sonia; LEITE, Maria Isabel Ferraz (Org.). Infância: fios e desafios da pesquisa. 10. ed. Campinas/SP: Papirus, p. 73-96, 1996.

MOLINA, Mônica Castagna; SÁ, Lais Mourão. Licenciatura em educação do campo. In: CALDART, Roseli Salete et al. (Org.). Dicionário da educação do campo. Rio de Janeiro, São Paulo: Expressão Popular, p. 446-472, 2012.

MST. Movimento dos Trabalhadores Rurais Sem Terra. Paulo Freire: um educador do povo. 2. ed. Rio Grande do Sul: Iterra, 2001.

OLIVEIRA, Admardo Serafim de. Paulo Freire: educação como prática de dominação ou de libertação. In: OLIVEIRA, Admardo Serafim de. Educação: redes que capturam caminhos que se abrem. Vitória/ES: Edufes, p. 19-34, 1996a. 
OLIVEIRA, Admardo Serafim de. Abordagem à filosofia do diálogo na pedagogia de Paulo Freire. In: OLIVEIRA, Admardo Serafim de. Educação: redes que capturam caminhos que se abrem. Vitória/ES: Edufes, p. 7-18, 1996b.

PAIVA, Jane. Compreensões da educação popular e questões que subsidiam a formação do educador. In: SANTOS, Renato Emerson dos et al. Educação popular, movimentos sociais e formação de professores: diálogos entre saberes e experiências brasileiras. Petrópolis, RJ: DP; Rio de Janeiro: Faperj, 2010.

SOUZA, Maria Antônia de. A educação do campo no Brasil. In: SOUZA, Elizeu Clementino de; CHAVES, Vera Lucia Jacob (Org.). Documentação, memória e história da educação no Brasil: diálogos sobre políticas de educação e diversidade. Tubarão/SC: Copiart, v. 1, p. 133-157, 2016.

VARGAS, Cristina Maria. Movimento Sem Terra, educação popular e um diálogo com os processos escolares. In: SANTOS, Renato Emerson dos et al. (Org.). Educação popular, movimentos sociais e formação de professores: diálogos entre saberes e experiências brasileiras. Petrópolis/RJ: DP et Alii, Faperg, 2010.

VIEIRA, Marle Aparecida Fidéles de Oliveira. Educação infantil do campo e formação continuada dos educadores que atuam em assentamentos. 2016. 210 f. Dissertação (Mestrado em Educação) - Universidade Federal do Espírito Santo, Vitória, 2016.

VIEIRA, Marle Aparecida Fidéles de Oliveira; CÔCO, Valdete. Da educação rural à educação do campo: percursos históricos da educação infantil a partir das produções acadêmicas e da legislação brasileira. In: SOUZA, Elizeu Clementino de; CHAVES, Vera Lucia Jacob (Org.). Documentação, memória e história da educação no Brasil: diálogos sobre políticas de educação e diversidade. Tubarão/SC: Copiart, v. 1, p. 83-105, 2016.

\section{SOBRE AS AUTORAS}

${ }^{1}$ Marle Aparecida Fideles de Oliveira Vieira - Mestra em Educação pela Universidade Federal do Espírito Santo (Ufes). Professora da rede municipal de Vitória/Espírito Santo.

E-mail: fidelesmarle@ gmail.com - ORCID: http://orcid.org/0000-0001-5460-5097

${ }^{2}$ Valdete Côco - Doutora em Educação pela Universidade Federal Fluminense (UFF). Professora no Departamento de Linguagens Cultura e Educação e no Programa de Pós-Graduação do Centro de Educação da Universidade Federal do Espírito Santo. E-mail: valdetecoco@ hotmail.com - ORCID: http://orcid.org/0000-0002-5027-1306 